\title{
Study on the Tensile Strength and Crack Development of Granite Crystal Models with Different Fabrics
}

\author{
Guangsheng Du $\mathbb{D}^{1,2}$ Shijiang Chen $\mathbb{D}^{1,2}$ and Zhihao $\mathrm{Li}^{1,2}$ \\ ${ }^{1}$ Institute of Mining Research, Inner Mongolia University of Science and Technology, Baotou, 014010 Inner Mongolia, China \\ ${ }^{2}$ Key Laboratory of Mining Engineering of Inner Mongolia, Baotou, 014010 Inner Mongolia, China \\ Correspondence should be addressed to Shijiang Chen; chenshijiang_2003@163.com
}

Received 2 March 2021; Revised 2 April 2021; Accepted 23 April 2021; Published 20 May 2021

Academic Editor: Haojie Lian

Copyright (C) 2021 Guangsheng Du et al. This is an open access article distributed under the Creative Commons Attribution License, which permits unrestricted use, distribution, and reproduction in any medium, provided the original work is properly cited.

\begin{abstract}
According to the relationship between the development of hydraulic fracture and the distribution of different rock and mineral fabrics, digital image technology was used in this study based on the discrete element particle flow method. An SCGM numerical model, which can control fabric and refine mesoscopic crystal defects, was constructed. The tensile strength test of granite specimens with different component contents and polymerization conditions was conducted, with the monitorization of damaged cracks. The test results showed that (1) the SCGM model could construct a model of a crystal structure containing variable components and polymerization, to achieve numerical experiments of different parameters; (2) compared with previous models, the SCGM model can reflect internal stress change of a specimen with the variation of the structure. At the same time, the contained crystal structure can characterize different failure modes such as intergranular cracks of different components, grain boundary cracks of the same component, and transgranular cracks, which were in good agreement with the actual failure state of granite; (3) the mica content of the specimen and its strength presented a linear relationship of $y=-14.723 x+12.642$. The degree of polymerization of the components and the strength of the specimens were both affected by the accumulation of microcracks and stress concentration, which appeared to increase first and then decrease. When the specimen was broken, the number of microcracks and the degree of polymerization of the components also increased first and then decreased. The SCGM model can construct a numerical model of granite with arbitrary fabric and crystal structure and provide a hydraulic fracturing analysis method.
\end{abstract}

\section{Introduction}

In recent years, as an important technical means in oil, gas, and hot dry rock exploitation, hydraulic fracturing technology has been widely used. In fact, in the construction process, the physical and mechanical properties of the rock itself have a great impact on the construction of hydraulic fracturing. Xia et al. [1-4] studied the crack propagation path of samples of heterogeneous rock with different microfractures by $\mathrm{CT}$ scanning 3D imaging technology, and it was found that the fractures of hydraulic fracturing were easy to generate along with the natural fractures and joints to interact with each other, forming complex network fractures. Therefore, the study of the relationship between the distribution of rock fab- ric and the fracture distribution can further promote understanding the hydraulic fracturing mechanism.

However, the failure mechanism of rock is very complicated. On the one hand, naturally formed cracks and pores within the rock have different effects on the rock's failure process; on the other hand, in the rock, various mineral components and crystals have different physical and mechanical properties [5, 6]. As shown in Figure 1, many scholars have interpreted the micromechanical damage inside the rock from the aspects of structure shape, size, and position of the mineral aggregation, crystal orientation, and grain boundary geometry to reveal rock strength characteristics and failure laws. Rock strength is suggested to be closely related to its microstructure $[7,8]$. 


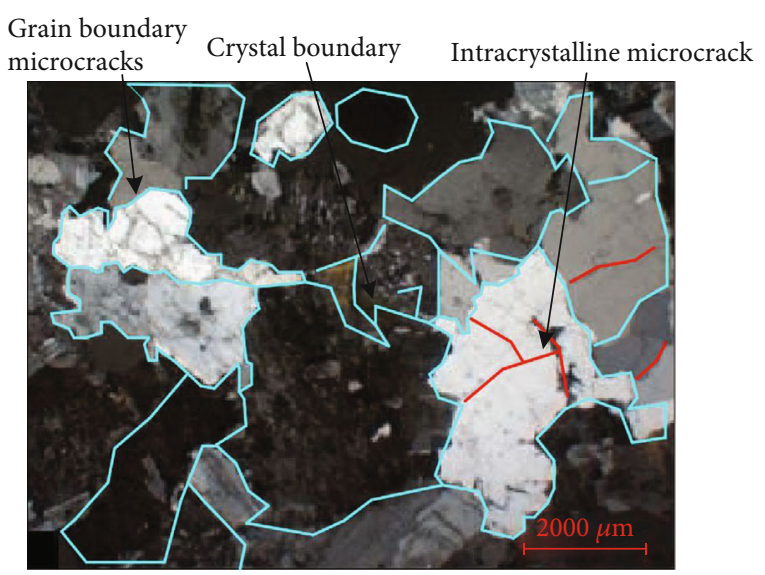

FIGURE 1: Micrograph of granite.

The fact is that the uniqueness of the rock structure makes it difficult to repeat the rock test accurately and control a specific variable of rock structure to study other influencing factors. Using the numerical simulation method to construct reusable rock samples for numerical experiments has become an effective method to solve rock mechanics problems.

In recent years, scholars have widely used discrete element numerical simulation technology to simulate rock mechanics tests because of its ability to effectively simulate the transfer relationship of internal rock forces. However, establishing a numerical model fitting the actual rock conditions best has been the focus of current research [9-12].

Many scholars have studied the mineral content and composition distribution of rock based on the discrete element method [13-24], which means identifying the surface information of the granite using digital image processing technology and importing it into numerical software in the form of vectorization to conduct a series of numerical experiments. It is proved that this method can reproduce the positional relationship between different fabrics of natural rock specimens to a great extent, making the numerical test results more realistic. By calibrating parameters through macroscopic experiments and considering the strength and modulus differences of different components, Jinzhao et al. [25] used digital image processing technology and other methods to construct a more consistent PFC numerical model containing different fabric information. Then, the peak strength and elastic modulus of rock were discussed. Although this method can effectively establish a numerical model consistent with the actual situation, it can only analyze a single specimen.

There are certain differences between the rock masses in the project and the experimental specimens, and it is not easy to obtain a specimen fully meeting the test requirements. Therefore, many scholars tried to fit the relationship between rock strength and internal microstructure using one or several functional relationships [26]. Considering the scale of spatial correlation based on the spatial correlation model, Tang et al. [27-30] analyzed the different continuous or aggregated components of rock and gave numerical images describing the aggregation form of different components of rock to build a numerical model that can adjust the distribution of rock components through parameters.

However, the rock crystal structure and internal joints and fissures were not fully considered in the previous modelling. Aiming at the mechanical properties of the crystal structure and the discontinuous surface inside the rock, Lv et al. $[31,32]$ used the Voronoi method to generate a numerical model in which the crystal structure and content can be controlled to analyze the relationship between the crystal grain size and the rock strength characteristic. This model is widely used in the formation of crystals of rocks. Cho et al. [33-36] proposed that the bonding state between the crystal grains in the rock is different from the mechanical state inside the crystal and introduced a massive cluster model to simulate the internal crystal structure. It was indicated that the cluster model could better express the mechanical relationship formed by the massive crystal structure inside the rock, but the particles in a clump cannot move and rotate in this model.

In fact, although a single component exhibits relatively uniform property, there are still differences, such as the arrangement of crystal structures and Poisson's ratios during crystallization. Considering the changes inside the crystal and the structure on the crystal boundary, Potyondy and Zhou et al. [37, 38] established a grain-based model (equivalent crystalline model) (GBM) composed of PBM and a smooth joint model. In this model, the internal components of the crystal are constructed by PBM, and SJM constructs the bonding relationship between the unit cells, making it more accurately reflect the mechanical relationship between the crystal and structure of the rock to study the relationship between the crystal size and rock strength characteristics. Li et al. and Zhang et al. [39, 40] combined the digital image technology and this numerical model to construct a particle flow numerical model, discussed and analyzed the advantages and rationality of the GBM model, and verified the effectiveness of the numerical model constructed by the model.

After reviewing previous research, it is easy to find that while constructing a numerical model, the refinement and the parameter controllability of the model were not fully considered. In this paper, a spatial correlation coefficient was adopted to rebuild the component structure of the rock surface through quantitative parameters (discretion of component distribution, component content). Simultaneously, the Voronoi model was used to construct the internal crystal structure of different components in which the particle size can be controlled. Then, the microfracture grid was imported through the improved GBM model to simulate the real defects, such as the naturally formed component boundary crystal structure of microcracks in the rock. Finally, a new modelling method of Spatially Correlated Grains Model (SCGM), which can adjust the internal parameters and describe the structure of the internal rock joints and fractures more accurately, was proposed and used to construct a numerical model to test the strength of granite specimens with different fabric characteristics. By comparing and analyzing the tensile strength of the specimens with different component content and distribution, the fracture 


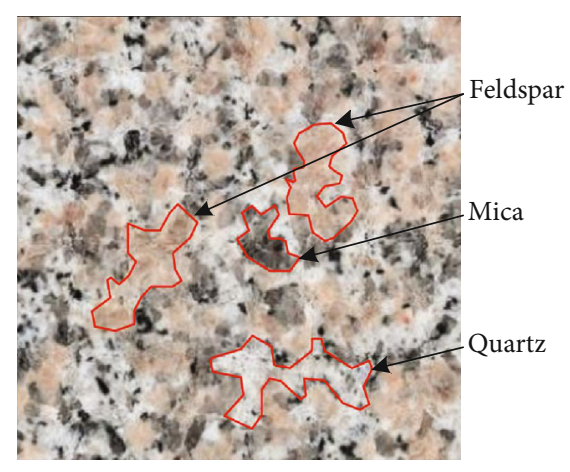

Figure 2: Actual granite image.

development law is further analyzed, providing a more accurate numerical method for the fracture analysis of hydraulic fracturing.

\section{Construction of Numerical Model SCGM}

In this study, PFC was used to conduct model construction and calculation. First, the component distribution was constructed through the spatial correlation function; secondly, the Voronoi model was used to construct the component's internal crystals; finally, the GBM model import method was used to construct the microcracks of the model specimen. The specific method is as follows.

\subsection{Construction of Component Distribution of Model} Specimens. Due to the influence of natural diagenesis processes, component distribution and physical and mechanical properties of rock materials are not entirely random; typically, different components and their properties show a certain degree of continuity and relevance in space. Figure 2 shows the section of natural granite; it can be seen that the inside of the same component keeps consistent in a large space. Tang et al. [27-30] introduced spatial correlation functions to describe these spatial distribution properties, which can be obtained by transforming the random field's spatial correlation function. With this method, image models of different component contents and distributions can be constructed to study heterogeneous materials and the influence of different spatial correlation coefficients on materials' mechanical properties. The results showed that this method was an effective method to construct the component distribution of granite specimens.

In this section, the spatial correlation function was used to construct the granite fabric. The steps are as follows.

(1) First, construct a random array, which is a matrix with two different label numbers. In this experiment, a $500 \times 500$ matrix $A$ with the element of $a_{i, j}$ was constructed, and the label numbers were 1 and -1 , respectively. Keeping $A$ unchanged, the calculated structure based on $A$ in the subsequent calculations has relative position stability

(2) Select the spatial correlation function that conforms to the generation state of such aggregated rocks:

$$
f(d)=e^{-d / L}
$$

where $d$ is the selected calculation distance; $L$ represents the spatial aggregation length, and it can indicate the degree of aggregation between the two regions when the value of $d$ remains unchanged. The smaller the $L$, the less the random field is affected by this function, which means that the original random state is maintained; otherwise, the state of aggregating will appear to a certain area. The rock fabric distribution affected by different material types and generation conditions can be obtained by changing this value. In this experiment, rock images with different spatial correlation degrees of $L=4,6,8$, and 10 were generated for different rock aggregation conditions, as shown in Figure 3

(3) Construct component spatial array for a given degree of aggregation. Multiply the elements in array $A$ by the correlation function $f(d)$ and parameter $C$ following the distance relationship, and superimpose them to obtain the array $B$ containing spatial correlation information according to the distance relationship. In this case, it means that the points within $d$ of a certain point are superimposed in the form of this distribution. Since the distribution characteristics of discrete points in a certain area are the same, the superposition will form a clustering effect. When the distance between the points is too large, the calculation amount will increase, and the influence on the aggregation point becomes small. Therefore, a reasonable calculation range needs to be selected. Tang et al. [30] analyzed the selected area of the function. Points within the distance $d=45$ were used for calculation in this paper. Array $B$ can be constructed as follows:

$$
b i, j=\sum_{p=-n}^{n} \sum_{q=-n}^{n} c d(p, q) \cdot a i+p, j+q f(d(p, q))
$$

where array $C$ is a variable coefficient indicating the degree of influence on an aggregation area under different distances. The smaller the distance, the closer the value of $c d(p, q)$ to 1

(4) Multicomponent distribution space construction of model specimens. It is suggested that the greyscale distribution of the granite surface image approximately conforms to the normal distribution, and the array calculated in this experiment also conforms to this characteristic. As shown in Figure 3, by adopting the technique of dividing granite components by the image grey threshold value and using the lowintensity component biotite as a reference, the generated images were divided into biotite with content $x$ $=10 \%, 15 \%, 20 \%, 25 \%$, and $30 \%$ when the corresponding feldspar and quartz content was gradually reduced. Then, the values in the matrix were divided into the form of Equation (3), and each division adopted the same set of matrices to make the 


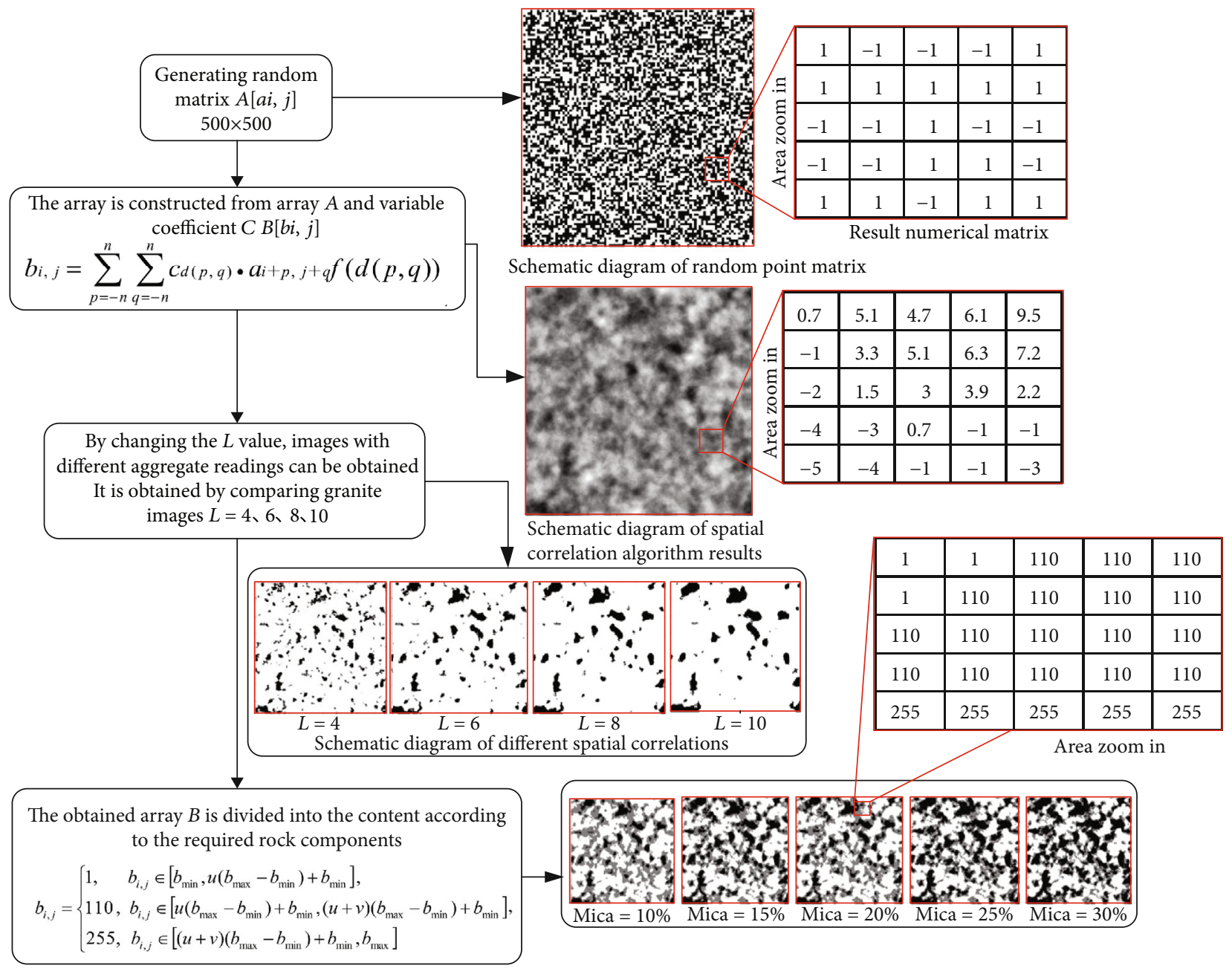

FIGURE 3: The construction process of the component distribution of the model specimen.

generated new matrix consistent with its image structure, which means that the position of mica, quartz, and other minerals in the image changed little except that their content area was expanded. Alternatively, a part of smaller blocks newly appeared within the threshold, as shown in Figure 3:

$b_{i, j}= \begin{cases}1, & b_{i, j} \in\left[b_{\min }, u\left(b_{\max }-b_{\min }\right)+b_{\min }\right], \\ 110, & b_{i, j} \in\left[u\left(b_{\max }-b_{\min }\right)+b_{\min },(u+v)\left(b_{\max }-b_{\min }\right)+b_{\min }\right], \\ 255, & b_{i, j} \in\left[(u+v)\left(b_{\max }-b_{\min }\right)+b_{\min }, b_{\max }\right],\end{cases}$

where $b_{i, j}$ represents the element value in the generated matrix, $b_{\max }$ and $b_{\min }$ are the maximum and minimum values in the matrix, $u$ is the percentage of mica content, and $v$ is the percentage of quartz content (Table 1)

2.2. Crystal Construction of Model Specimen. In the study of rock mesoscale, it is found that under the impact of loading, rock failure can be categorized into three types, including grain boundary cracks of different components, large crystal
TABle 1: The content of different components in the generated image.

\begin{tabular}{lccccc}
\hline Component & \multicolumn{5}{c}{ Content } \\
\hline Mica & $10 \%$ & $15 \%$ & $20 \%$ & $25 \%$ & $30 \%$ \\
Quartz & $40 \%$ & $37.5 \%$ & $35 \%$ & $32.5 \%$ & $30 \%$ \\
Feldspar & $50 \%$ & $47.5 \%$ & $45 \%$ & $45.5 \%$ & $40 \%$ \\
\hline
\end{tabular}

cracks of the same composition, and transgranular cracks [41, 42]. The main factors leading to rock failure include the internal discontinuous surface, their distribution, and the ultimately formed stress concentration. Therefore, it is not enough to only discuss the composition distribution of the rock. The grain boundary cracks of different compositions and the large crystal cracks of the same composition need to be represented separately. The Voronoi crystal generation method is widely used to simulate the generation of crystals such as rocks, which is used to generate a crystal particle model within the composition region above so as to adjust the average size. Combining the component boundaries of the image and the crystal grains within the component, a model simultaneously considering the component 


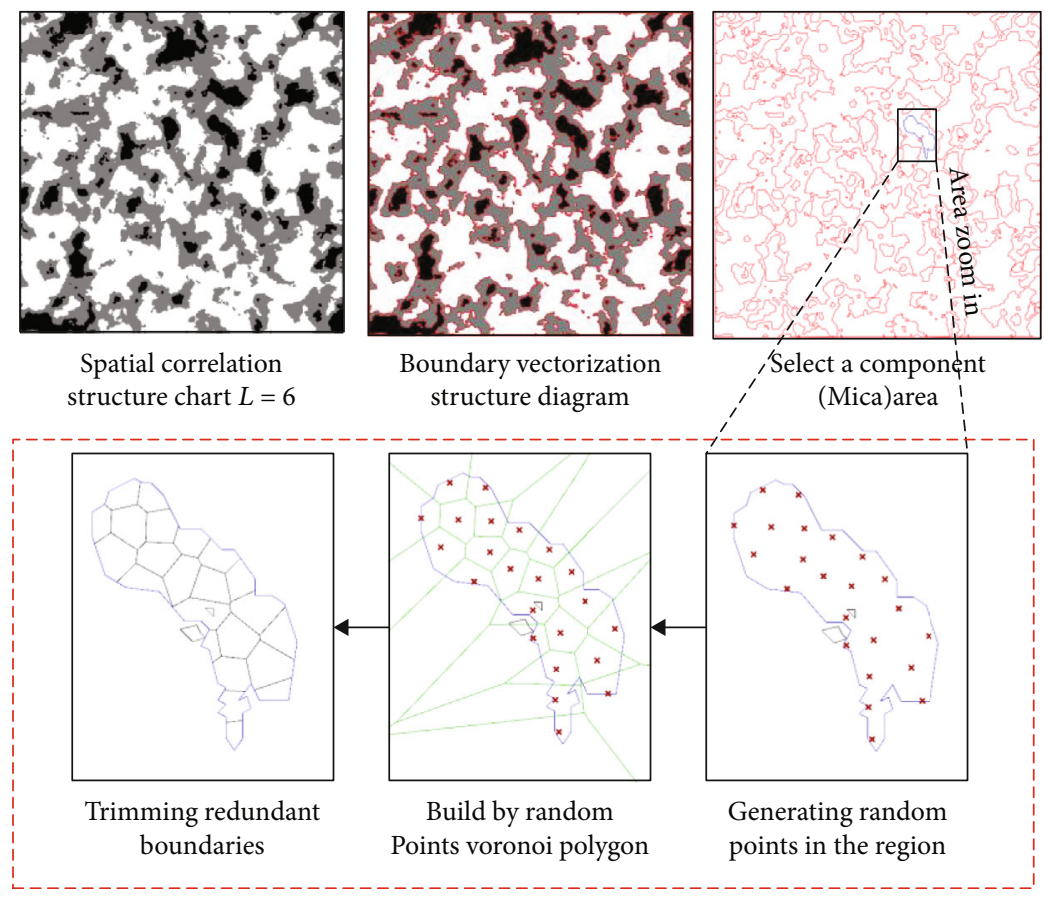

FIGURE 4: Generation diagram of the internal crystal structure in a certain area.

structure relationship and the crystal discontinuous surface relationship was generated. The vector structure model generation steps are as follows:

(1) Recognize the image containing spatial correlation information, and component content was divided and calibrated with grey values of 1,110 , and 255; that is, the positions with an abrupt change of grey value are segmented at the component boundary, and the segmentation position is closed as a region (Figure 4)

(2) Construct the unit cell structure inside the divided components, import the vectorized boundary into the drawing software Rhinoceros to adjust the size, and remove the unnecessary boundary

(3) By acquiring and observing the real granite surface images, the average radius of feldspar, quartz, and mica crystals was determined as $1.6 \mathrm{~mm}, 1.5 \mathrm{~mm}$, and $0.9 \mathrm{~mm}$; then, uniformly distributed random points matching area scales were generated to construct the internal crystal structure of the components according to the Voronoi polygon rule, as shown in Figure 4

2.3. Construction of Microcracks in Model Specimens. In order to describe the discontinuous crystals in rocks, Potyondy proposed the SJM model, which can simulate the sliding state with a certain amount of overlap after the strength is lost. Li et al. and Zhang et al. $[39,40]$ used the GBM model to construct a refined numerical model conforming to the distribution of the granite surface structure and carried out an analysis of the mesoscopic mechanical structure of the image components to explain the relationship between the mesoscopic mechanical properties and the macroscopic failure of rocks. Therefore, the GBM model is used to build a granite numerical model, as shown in Figure 5.

2.4. SCGM Model Generation Process. Based on the research on the strength of different rock fabrics and the refined construction of rock crystal structure models, the SCGM model was constructed by combining the above three sections, as shown in Figure 6.

The specific process is as follows:

(1) Generate granite surface images with different distributions and component structures through spatial correlation functions

(2) Divide the obtained image into vectorization (connect each component block to form a closed area)

(3) Generate a Voronoi model to represent crystal particles through random points in each closed area

(4) Firstly, generate a uniform specimen in the PFC2d software, and then, import the vectorized image to group the different components in order by layer

(5) Import the images containing crystal grain boundaries into the software to group the models and parameters in the order of layers

(6) Adjust the mesoscopic parameter

2.5. Parameter Calibration of PFC Numerical Model. In order to match the results of the numerical test with the actual rock 


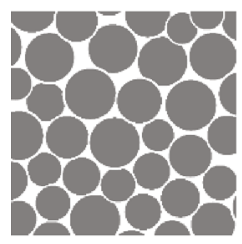

Initial particles

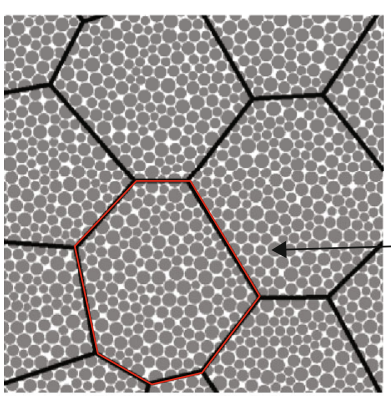

Importing crystal structure network

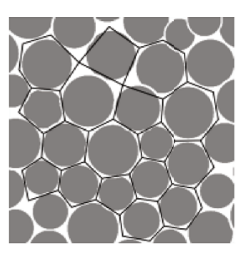

Building crystals

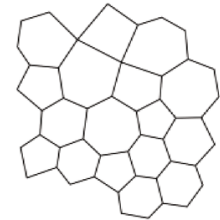

Crystal network

Figure 5: Generation diagram of new GBM model.

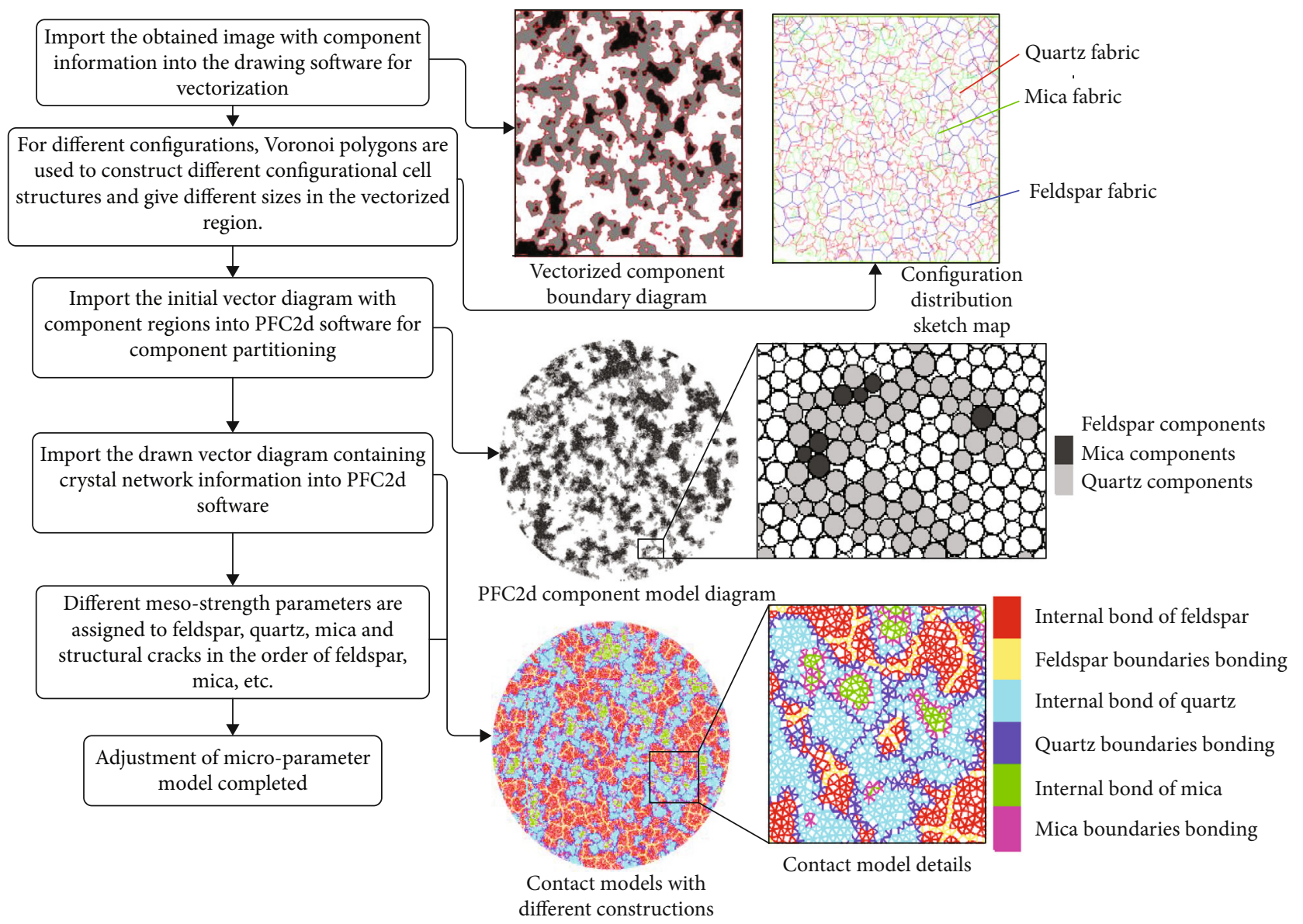

FIGURE 6: Generation process of SCGM model.

failure better, it is necessary to calibrate parameters in the numerical model. The calibration method in this paper is to match the strength and the elastic modulus in the actual physical test within a certain range [43-48]. Considering the internal structure of the rock, the strength between rock crystals was set to be $40 \%$ of the internal strength of rock 
TABLE 2: Mesoscopic parameters of particles of different components.

\begin{tabular}{|c|c|c|c|c|c|c|c|}
\hline Mineral component & $\begin{array}{l}\text { Minimum radius } \\
(\mathrm{mm})\end{array}$ & $\begin{array}{c}\text { Radius } \\
\text { ratio }\end{array}$ & $\begin{array}{l}\text { Density } \\
\left(\mathrm{kg} / \mathrm{m}^{3}\right)\end{array}$ & $\begin{array}{l}\text { Parameters } \\
\text { Elastic modulus } \\
\qquad(\mathrm{GPa})\end{array}$ & $\begin{array}{l}\text { Stiffness } \\
\text { ratio }\end{array}$ & $\begin{array}{l}\text { Friction } \\
\text { coefficient }\end{array}$ & Void ratio \\
\hline Feldspar & & & 2750 & 45 & 1.5 & 0.6 & \\
\hline Quartz & 0.15 & 1.66 & 2650 & 61 & 1.5 & 0.7 & 0.025 \\
\hline Mica & & & 3100 & 20 & 2.5 & 0.3 & \\
\hline
\end{tabular}

TABle 3: Mesoscopic parameters of different component contact models.

\begin{tabular}{|c|c|c|c|c|c|c|}
\hline \multirow[b]{2}{*}{ Mineral component } & \multicolumn{6}{|c|}{ Parameters } \\
\hline & $\begin{array}{l}\text { Volumetric modulus } \\
(\mathrm{GPa})\end{array}$ & $\begin{array}{l}\text { Stiffness } \\
\text { ratio }\end{array}$ & $\begin{array}{l}\text { Tensile limit } \\
(\mathrm{MPa})\end{array}$ & $\begin{array}{l}\text { Cohesion force } \\
(\mathrm{MPa})\end{array}$ & $\begin{array}{c}\text { Friction angle } \\
\left({ }^{\circ}\right)\end{array}$ & $\begin{array}{c}\text { Friction } \\
\text { coefficient }\end{array}$ \\
\hline Feldspar & 45 & 1.5 & 53.2 & 53.0 & 15 & \\
\hline Quartz & 61 & 1.5 & 68.2 & 60.1 & 17 & 0.67 \\
\hline Mica & 20 & 2.5 & 23.1 & 25.1 & 17 & \\
\hline Feldspar structure & 40 & 1.5 & 20.5 & 23.1 & 16 & \\
\hline Quartz structure & 40 & 1.5 & 25.1 & 22.5 & 15 & 0.85 \\
\hline Mica structure & 40 & 2.5 & 10.5 & 12.1 & 15 & \\
\hline
\end{tabular}

crystals referring to the study of $\mathrm{Hu}$ et al. [49-51]. Simultaneously, referring to the strength differences between different minerals in the rock, the strength ratio of feldspar, quartz, and mica inside the granite was set as $0.8: 1: 0.3$. In order to ensure high accuracy of the matched parameters, the component distribution of the real granite specimen was obtained through digital image processing, (Tables 2 and 3 ) the matching process is shown in Figure 7 , and the result is shown in Figure 8.

\section{Validation of Tensile Test of SCGM Numerical Model Specimen}

The SCGM model was constructed and tested following the above scheme, and the result data was collected. The numerical simulation adopted the same scheme as the indoor test and monitored the tensile strength of the rock using the Brazilian split test. The stress distribution changes of heterogeneous specimens, the influence of the crystal structure on the failure of specimens, and the influence of different structural parameters on the development of cracks after specimens were broken were described, respectively.

3.1. Fabric Impact Analysis. While analyzing the initial Brazilian split tensile strength, the specimen was regarded as a homogeneous specimen, so the stress distribution on the surface was in the symmetric and uniform state [52, 53], as shown in Figure 9. However, the internal stress distribution of the specimen is affected by many factors, such as the different modulus of different components, the sliding, and stress concentration of the discontinuous surface. These factors cause the internal stress to nonlinearly change with the loading position, as shown in Figure 9. It can be seen that the internal stress of the rock was not smooth along the loading axis but showed a certain irregular change with the composition when the rock end was subjected to the load. Larger ten- sile stress appeared near the lower right in the $x$-direction stress diagram; a certain amount of feldspar and quartz was distributed at this position, which is corresponding to the fabric distribution of the actual specimen; at the same time, because their strength and modulus are higher than mica, it will not instantly produce microdestruction and dislocation under load. In contrast, a large amount of elastic energy was accumulated, and deformation appeared to gradually form tensile stress in this direction. There was a large amount of mica component on the upper part of the test piece, which had low strength and small tangential deformation. It is easy to produce partial tension cracks and form partial sliding, making it not form effective tensile stress but apparent compressive stress. It can be clearly seen from the structural diagram that the distribution of stress is highly correlated with the corresponding relationship between the fabric in the specimen.

3.2. Crystal Structure Impact Analysis. Due to the convenience of the spatial correlation function, Wenmin [54] constructed a numerical model with different correlation coefficients and discussed the influence of different correlation coefficients and anisotropy parameters on the strength and failure state of the specimen. However, only the strength parameters of different mineral components were discussed in the numerical model, but the internal structural problems were not analyzed in detail. There are a large number of cracks and voids in the natural rock mass, especially the internal crystal interface that needs to be paid attention to. In this paper, the constructed model considered the crystal network structure of different components; Brazil splitting tests were performed on two different models. As shown in Figure 10, under the same mesoscopic parameter, the strength of the SCGM model was lower than that of the PBM model, about $87 \%$ of the strength of the PBM model, and the deformation was not much different. As shown in Figure 11, the two models showed obvious differences in 


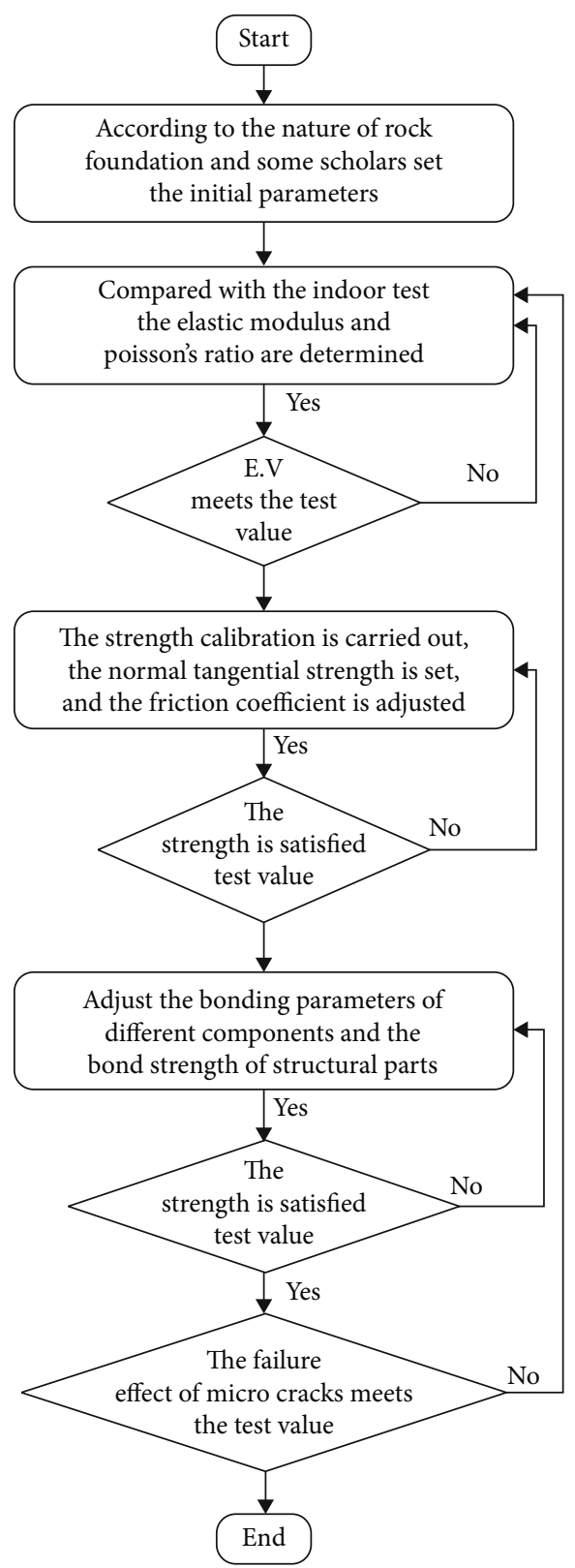

Figure 7: Calibration process of mesoscopic parameters in the numerical model.

the development of the damage cracks; at a certain special location in the same composition area, damage cracks in the SCGM model occurred obvious deflection because of a crystal interface, which is more consistent with the actual situation. During the failure process, the development of cracks in the SCGM model can better reflect the changes in the natural structure of the rock under force, and the model will produce grain boundary cracks of different components, large crystal cracks of the same composition, transgranular cracks, and more obvious secondary cracks. However, the PBM model cannot reflect these characteristics.

3.3. Realization of Tensile Test of Arbitrary Rock Fabric. The construction of a refined numerical model is of great significance to the study of rock mechanics. By identifying the structure image of the rock surface component and constructing the model based on this, semicircular surface structure load strength of 16 granites was analyzed and compared with that of the structure generated by Voronoi. The real rock structure can be obtained by modelling using the original rock surface image, which helps the analysis of a single rock specimen. However, this method has many limitations while performing the horizontal comparison, such as analysis of the same component content in different locations, analysis of different component content in the same location, and controlling component changes and crystal size. As shown in Figure 12, the SCGM model can solve these problems more effectively. The spatial correlation function image can set the distribution and content of granite components, and the Voronoi model can set different grain sizes. It can be seen that the cracks tend to be more stable during the development process as the dispersion of the component distribution decreased; for the $L=4$ specimen, the mica was more discretely arranged in the specimen; then, the cracks would develop in multiple directions during the loading process. As the $L$ value increased, the composition distribution and the low-strength structure tended to be stable. At this time, the development direction of the cracks gradually becomes single. As the content of mica increased, the percentage of low-strength structures also increased, and the number of microcracks when the specimen was damaged also increased. Moreover, many apparent cracks break along the crack network structure.

In previous studies, it has been shown that the failure of rocks is mainly caused by the expansion and development of internal microcracks, which eventually converge into larger macrocracks. Therefore, the strength of the rock has an apparent relationship with the crack state. On the one hand, the development status of cracks is related to the distribution of different components in the rock; on the other hand, it also correlates with each component's content. For these two influencing factors, the SCGM model was used to construct granite specimens with different discrete distributions and component contents, and split tests were carried out to analyze the relationship between the different fabric contents and the distribution of granite strength and cracks.

In this experiment, the parameters of spatial correlation coefficient $L=4,6,8$, and 10 (that is, the dense distribution of different components) were selected, and different component contents $x=10 \%, 15 \%, 20 \%, 25 \%$, and $30 \%$ were constructed in each spatial correlation coefficient by referring to the mica; the peak strength of each specimen was counted. Because of the smallest particles, a certain error will occur while constructing the model. Therefore, all models have performed 10 tests under the condition of different random seeds. The result is shown in Figures 13 and 14 .

It can be seen from Figure 13 that for all distribution states of the component, as the mica content increased, the peak tensile strength all showed a downward trend with a relatively obvious linear change. By fitting the average value of the peak strength change and the mica content, the function of the variation law of the peak strength under different mica contents was obtained, $y=-14.723 x+12.642, R^{2}=0.9444$, 


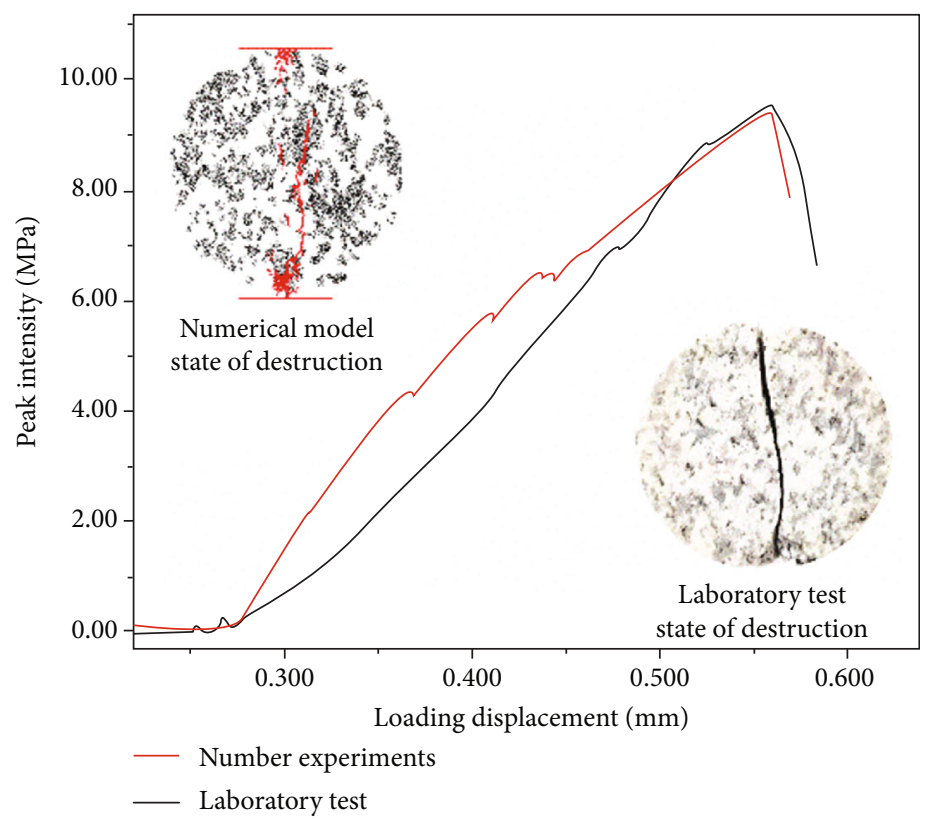

FIGURE 8: Calibration results of mesoscopic parameter in the numerical model.

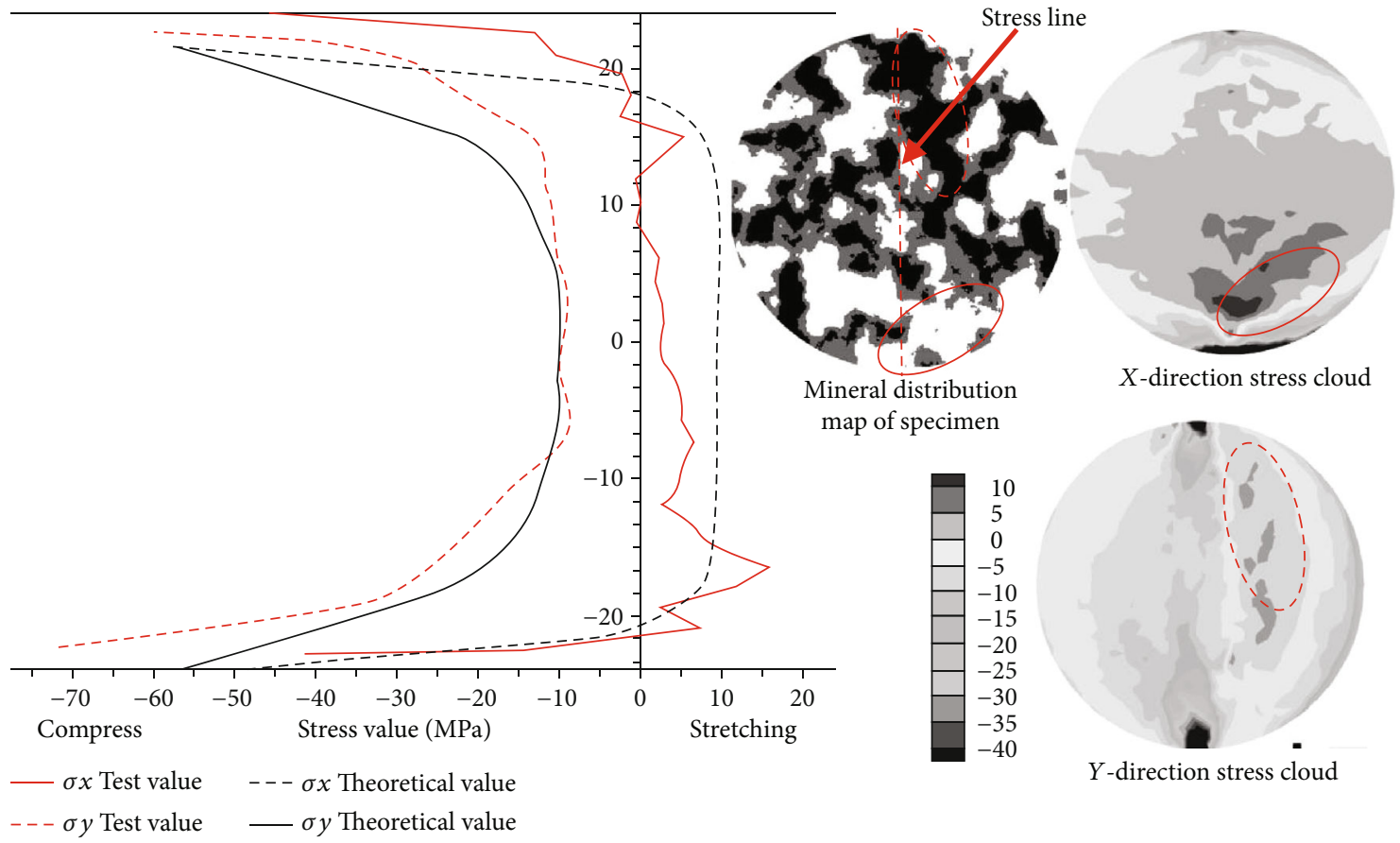

FIGURE 9: Schematic diagram of stress distribution along the loading direction.

where $x$ is the mica content and $y$ is the peak strength. However, there were certain fluctuations during the decline; this is because although the consistency of the recomposition distribution of the test piece was maintained, a certain change in the external morphology would produce a certain articulated surface to make the test piece stable under a certain structure with the increase of the mica content; moreover, although the Voronoi structure in different component structures was established with the same method and parameters, the initial scattered point positions were randomly distributed, which led to certain volatility, but the tensile strength of the specimen decreased as the mica content increased.

It can be seen from Figure 14 that the strength of the specimen apparently first increased and then decreased with the value of $L$, which became obvious when the mica was $10 \%, 20 \%$, and $30 \%$. The average strength of the specimens with $L=4,6,8$, and 10 was $9.706 \mathrm{MPa}, 10.156 \mathrm{MPa}$, $9.908 \mathrm{MPa}$, and $9.228 \mathrm{MPa}$. Through comparative analysis, 

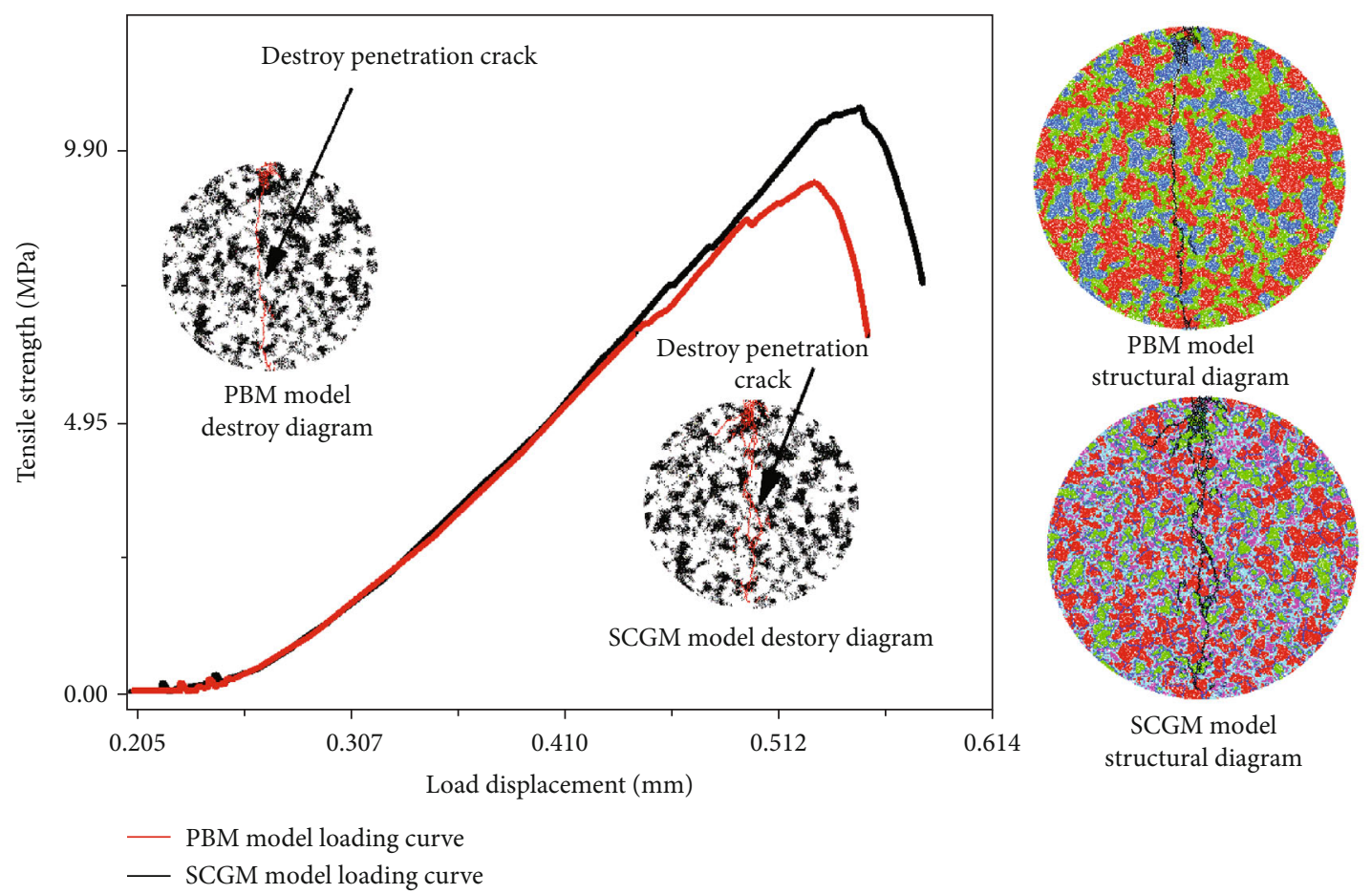

FIGURe 10: Brazil split test results of SCGM and PBM models.
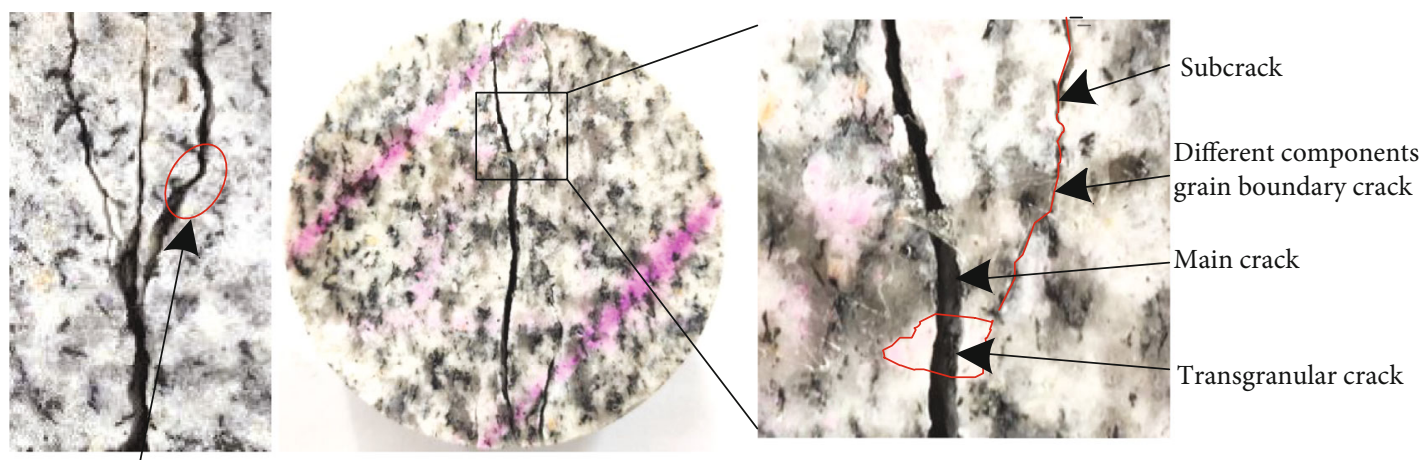

Crystal boundary cracks of the same composition

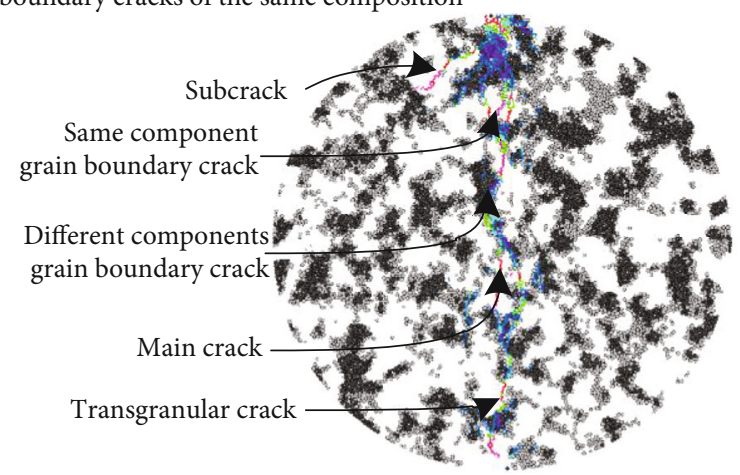

SCGM model structure diagram

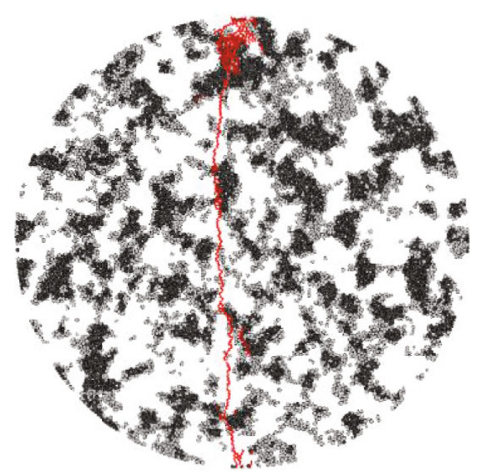

PBM model structure diagram

FIgURE 11: Modelling and actual splitting effect of spatial correlation function structure crystal.

it is found that the main reason for this phenomenon is that when $L$ was small, the low-strength parts such as mica and its joints and cracks were distributed throughout the specimen; with the same content, the more scattered the distribu- tion, the longer the length of the boundary joints. At this time, the strength of the whole specimen was weaker. On the contrary, when a large number of components were gathered, the length of the boundary joint decreased, and 


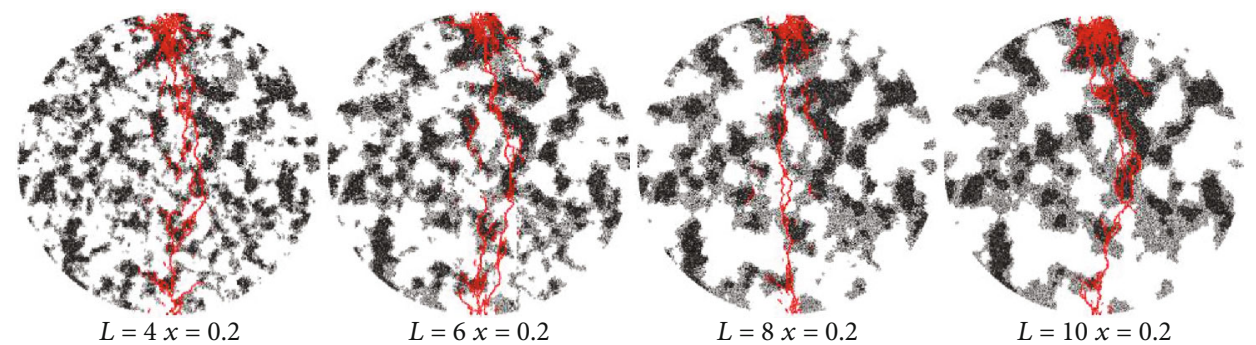

(a)

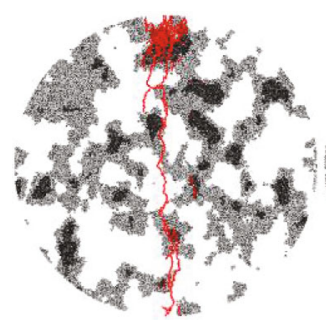

$L=8 x=0.1$

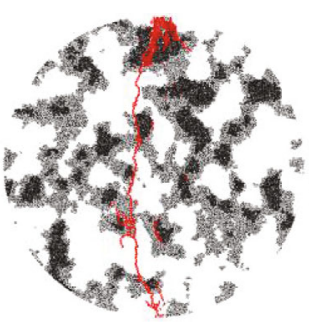

$L=8 x=0.15$

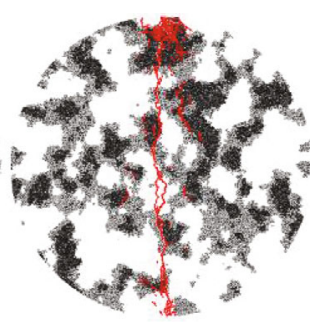

$L=8 x=0.2$

(b)

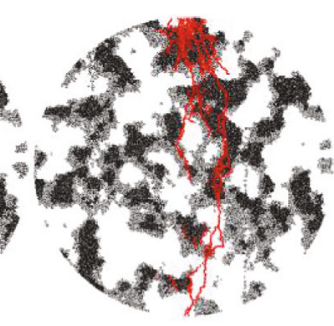

$L=8 x=0.25$

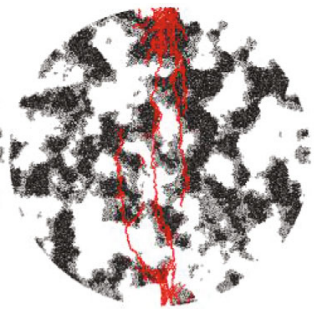

$L=8 x=0.3$

Figure 12: Brazil split test results with different structural parameters and component contents. (a) Fracture development diagram of specimens with different spatial correlation coefficients. (b) Fracture development diagram of specimens with different component contents.

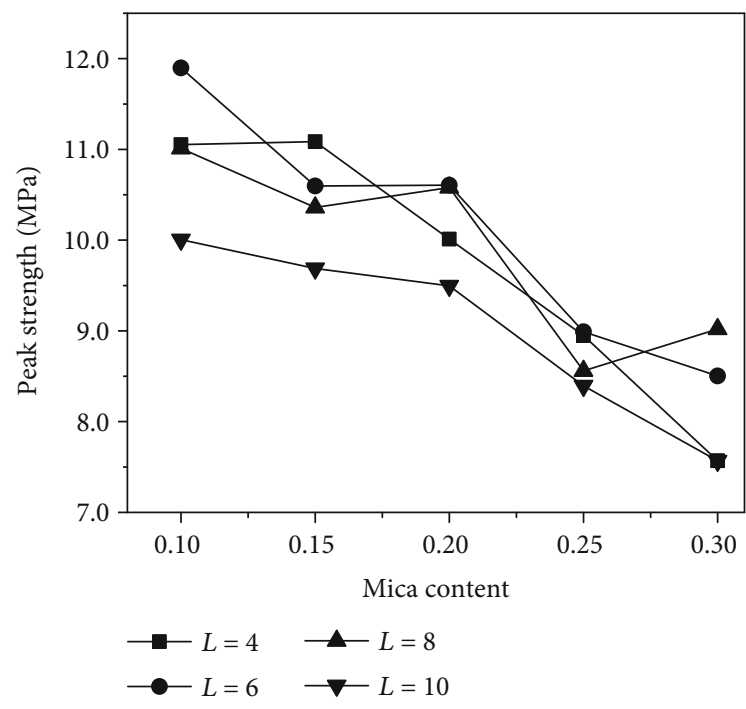

Figure 13: The relationship between the peak strength and the content of mica.

the specimen's overall strength increased. When the mica content was $x=20 \%$, and $L=4,6,8$, and 10 , the mica boundaries were $15.34 \%, 12.31 \%, 10.45 \%$, and $9.83 \%$, respectively. The boundary content obviously gradually decreased, but the strength of the specimens first increased and then decreased, which means that when the mica component was sufficiently large, a certain degree of stress concentration advantage will be formed, resulting in a decrease in its strength. Combining the above two reasons, the peak strength of the specimen first increased and then decreased with the value of $L$.

3.4. Analysis of the Relationship between Crack Development and Fabric. The macroscopic failure and instability of rock

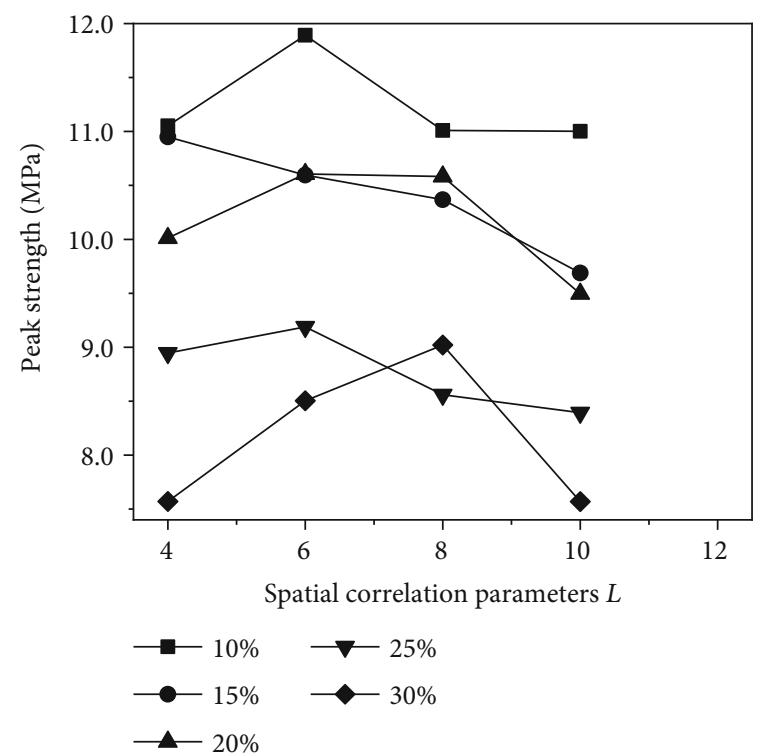

FIGURE 14: The relationship between the peak strength and the change of $L$.

can be attributed to the gradual development and growth of internal microcracks under loading and finally converged into larger microcracks which causes the rock to fail eventually. Therefore, the analysis of internal rock fractures is helpful to understand the destruction mechanism furtherly.

The microfracture was monitored through the crack generation program of the PFC software. The principle is to set the monitoring distance between particles and the strength between particles. When the external load identification force reached this strength, a crack will be recorded. The particle size determines the crack size, which follows a normal 
distribution with the size between 0.15 and $0.256 \mathrm{~mm}$ in this test; therefore, the crack size is also within this range. During the monitorization, the cracks of different components were grouped and performed statistics. As shown in Figure 15, regardless of the degree of polymerization, the number of cracks in the specimen and mica content showed a trend of increasing first and then decreasing with a peak state when mica content was $20 \%$. The reason is that on the one hand, as the mica content increased, the number of low-strength components increased, and the total number of cracks increased; on the other hand, as the content increased, a large number of low-strength mica gathered to form stress concentration, leading to a rapid rupture of the specimen and making the cracks unable to develop to a large scale for when the number of cracks decreased.

The total number of cracks was counted as 5601, 5734, 5085 , and 4797 when $L=4,6,8$, and 10 are, respectively, showing the trend of increasing first and then decreasing. On the one hand, the number of cracks reflects the required destruction energy, and it can remain stable when more cracks have been generated, which means more energy is absorbed; on the other hand, it means that the structural stability of the area is high, and for many microcracks, it is still difficult to form macroscopic damage. Therefore, the specimen is stable with higher strength when $L=6$, as shown in Figure 14.

As shown in Figure 16, as the value of $L$ increased, the distribution of cracks gradually shifted from the external crystal to the destruction of the inside crystal. The proportion of cracks in the structural cracks decreased as the $L$ value increased. The internal strength of the crystal was greater than the intercrystal structure strength. When there were more cracks in the crystal, more force and energy were required. This is also a fundamental reason for the nonlinear relationship between the strength of the specimen and the $L$ value. By monitoring the cracks between the different component structures in Figure 17, it can be found that the cracks of the feldspar structure increased with the increase of $L$, and the proportions of the structural cracks of the quartz and mica both decreased with the increase of $L$. Numerically, it can be seen that the main contribution of the proportion of structural cracks in the whole specimen is provided by the proportion of structural cracks in mica, but its fluctuation is affected by the combined effects of the three components.

\section{Discussion}

Experiments showed that the SCGM model was used to construct the numerical test piece so that the structure of the component boundary and the discontinuous surface between the crystal particles within the component can be generated inside the model, and the quantitative construction of the component structure of the crystal model was realized at the same time. However, there is a problem worthy of being discussed: the determination of the strength parameters of the structure between different rock components. At present, the method of referring to the actual failure of the specimen and the peak strength elastic modulus

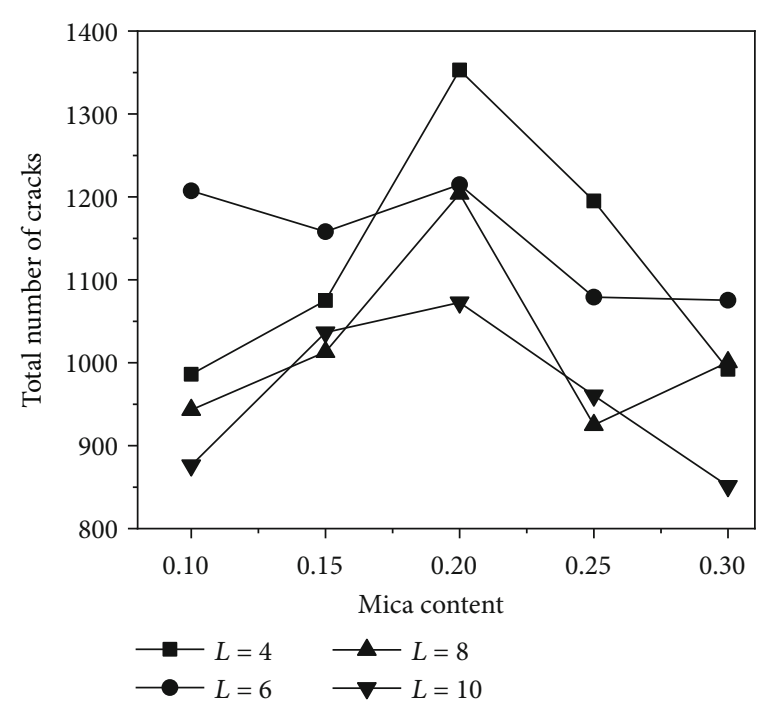

Figure 15: The relationship between the number of cracks and the content of mica.

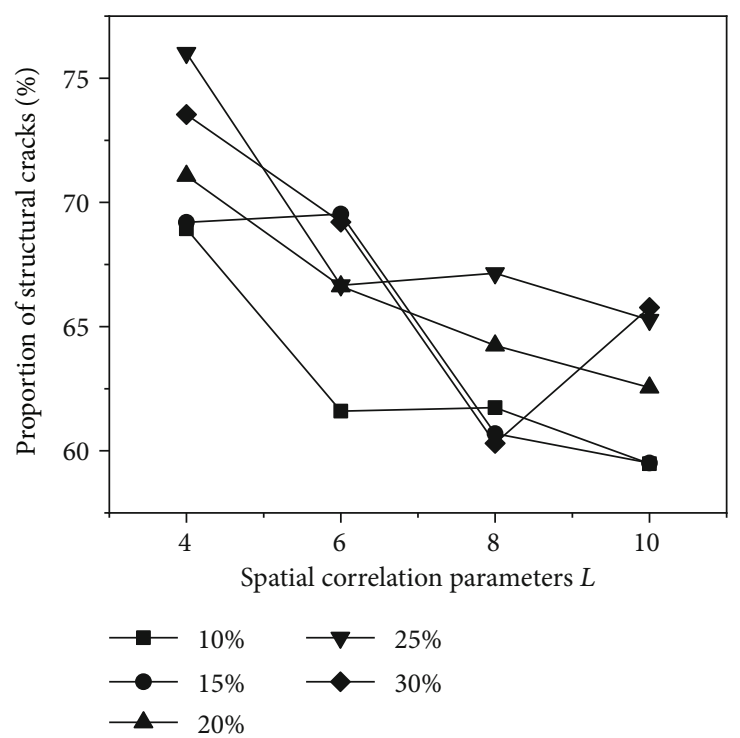

FIGURE 16: The relationship between the proportion of microcracks and the $L$ value.

is usually used, but in fact, the value of the strength between different components of rock has always been in a fuzzy state. Some scholars choose a certain weakening factor $\alpha$ between 0 and 1 to reflect the reduction of its strength based on experience. When the timing $\alpha$ and other component parameters are double-calibrated, there may be multiple sets of solutions; that is, the final rock strength represented by different $\alpha$ and its corresponding strength parameters are consistent. Therefore, with the help of the SCGM model and more actual parameters, calibration and analysis of $\alpha$ parameters are of great significance. It can further advance the analysis and research of rock fracture development. 


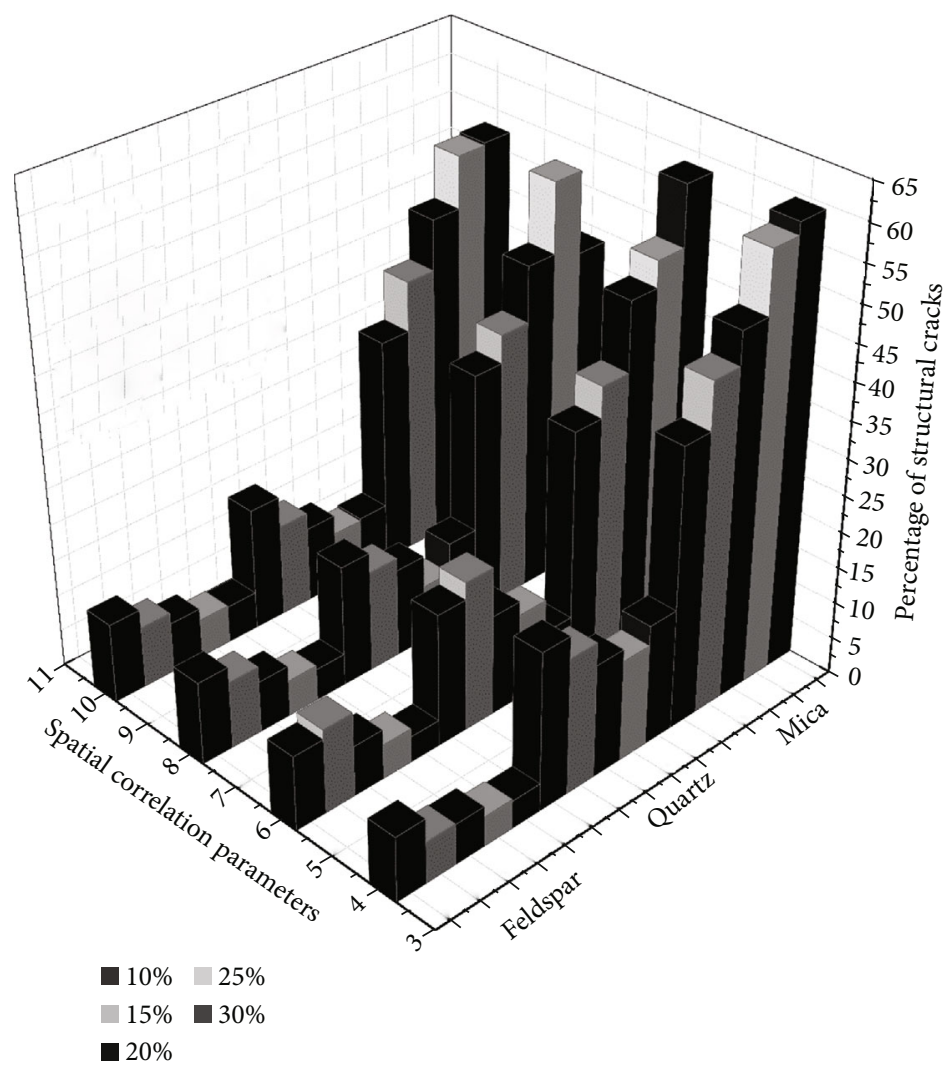

FIGURE 17: The relationship between the content of microcracks in different components and the $L$ value.

\section{Conclusion}

Considering the fracture development of different fabric granite during hydraulic fracturing, the spatial correlation function was used to construct a digital image of the granite surface, which solved quantitating testing of the rock structure. Besides, a numerical model containing the internal crystal structure of the rock was constructed through the Voronoi model and the GBM import method. The newly formed SCGM model has more evident advantages in representing the fracture development of rock failure. Combining the advantage of the SCGM model, the relationships between the distribution and content of the internal components of the granite and its tensile strength were analyzed, as well as the cracks developed in the boundary structure and the crystal. The results are as follows.

(1) The spatial correlation function can generate a granite surface image with a controllable structure content by adjusting the parameters. Combining this method with the discrete element numerical model of the internal crystal structure, a numerical model of the granite with adjustable structural parameters can be constructed more accurately to perform numerical experiments

(2) Compared with the homogeneous model, internal stress of the SCGM model changed with the structure distribution, which was more consistent with the actual rock specimen. Compared with the PBM model, the internal crystal structure constructed by the new model can better reflect the internal mechanical relationship of rock. Compared with laboratory experiments, the model with internal crystals showed intergranular cracks of different components, grain boundary cracks of the same composition, and transgranular cracks when granite fails. Compared with actual granite image modelling, the method had strong controllability and can construct accurate models for different discrete situations and component contents

(3) The Brazilian splitting numerical experiments of different fabrics showed that the strength of the specimen decreased significantly with the increase of the mica component content and showed a linear change $y=-14.723 x+12.642$; the strength of the specimen increased with the increase of the spatial correlation coefficient $L$, showing a certain trend of increasing first and then decreasing. By monitoring the cracks in the failure process, the total number of cracks showed the trend of first increasing and then decreasing with the increase of the internal mica content. Moreover, it existed a clear peak when the mica content was 20\%; on the crystal interface, the ratio of cracks to the total cracks decreased with the increase 
of $L$, and the result was more obviously affected by the mica component

(4) The test results show a significant correlation between fracture development and fabric distribution of different fabric rocks under external load, and corresponding technologies should be adopted for different fabric rocks in hydraulic fracturing

\section{Data Availability}

(1) The picture data used to support the findings of this study are included within the article. (2) The chart data used to support the findings of this study are included within the article. (3) The flow chart data used to support the findings of this study are included within the article.

\section{Conflicts of Interest}

The authors declare that they have no conflicts of interest.

\section{References}

[1] B. W. Xia, X. Zhang, B. Yu, and J. Jia, "Weakening effects of hydraulic fracture in hard roof under the influence of stress arch," International Journal of Mining Science and Technology, vol. 28, no. 6, pp. 951-958, 2018.

[2] Z. Yushi, Z. Shicheng, Z. Tong, Z. Xiang, and G. Tiankui, "Experimental investigation into hydraulic fracture network propagation in gas shales using CT scanning technology," Rock Mechanics and Rock Engineering, vol. 49, no. 1, pp. 3345, 2016

[3] J. He, C. Lin, X. Li, Y. Zhang, and Y. Chen, "Initiation, propagation, closure and morphology of hydraulic fractures in sandstone cores," Fuel, vol. 208, pp. 65-70, 2017.

[4] Z. H. Wang, W. G. Ren, Y. L. Tan, and H. Konietzky, "Experimental and numerical study on hydromechanical coupled deformation behavior of Beishan granite considering permeability evolution," Geofluids, vol. 2020, Article ID 8855439, 14 pages, 2020.

[5] D. Krajcinovic, "Damage mechanics: accomplishments, trends and needs," International Journal of Solids and Structures, vol. 37, no. 1-2, pp. 267-277, 2000.

[6] R. Prikryl, "Some microstructural aspects of strength variation in rocks," International Journal of Rock Mechanics \& Mining Sciences, vol. 38, no. 5, pp. 671-682, 2001.

[7] A. Luque, E. Ruiz-Agudo, G. Cultrone, E. Sebastián, and S. Siegesmund, "Direct observation of microcrack development in marble caused by thermal weathering," Environment and Earth Science, vol. 62, no. 7, pp. 1375-1386, 2011.

[8] R. Peng, Y. Ju, J. G. Wang, H. Xie, F. Gao, and L. Mao, "Energy dissipation and release during coal failure under conventional triaxial compression," Rock Mechanics and Rock Engineering, vol. 48, no. 2, pp. 509-526, 2015.

[9] G. Ma, C. Zhou, X. Chang, and Z. Wei, "Continuous-discontinuous coupling analysis for whole failure process of rock," Chinese Journal of Rock Mechanics and Engineering, vol. 30, pp. 2444-2455, 2011.

[10] R. Abousleiman, G. Walton, and S. Sinha, "Understanding roof deformation mechanics and parametric sensitivities of coal mine entries using the discrete element method," Interna- tional Journal of Mining Science and Technology, vol. 30, no. 1, pp. 123-129, 2020.

[11] R. Cao, H. Lin, and P. Cao, "Strength and failure characteristics of brittle jointed rock-like specimens under uniaxial compression: digital speckle technology and a particle mechanics approach," International Journal of Mining Science and Technology, vol. 28, no. 4, pp. 669-677, 2018.

[12] J. Qiu, L. Luo, X. Li, D. Li, Y. Chen, and Y. Luo, "Numerical investigation on the tensile fracturing behavior of rockshotcrete interface based on discrete element method," International Journal of Mining Science and Technology, vol. 30, no. 3, pp. 293-301, 2020.

[13] Y. G. Zhang, J. Qiu, Y. Zhang, and Y. Wei, "The adoption of ELM to the prediction of soil liquefaction based on CPT," Natural Hazards, vol. 107, 2021.

[14] Y. G. Zhang, J. Tang, R. P. Liao et al., "Application of an enhanced BP neural network model with water cycle algorithm on landslide prediction," Stochastic Environmental Research and Risk Assessment, vol. 46, 2020.

[15] S. Lv, S. Wang, R. Li, G. Li, M. Yuan, and J. Wang, "Prediction of coal structure using particle size characteristics of coalbed methane well cuttings," International Journal of Mining Science and Technology, vol. 29, no. 2, pp. 209-216, 2019.

[16] Y. G. Zhang and L. N. Yang, "A novel dynamic predictive method of water inrush from coal floor based on gated recurrent unit model," Natural Hazards, vol. 105, no. 2, pp. 20272043, 2021.

[17] Y. G. Zhang, Z. Zhang, S. Xue, R. Wang, and M. Xiao, "Stability analysis of a typical landslide mass in the Three Gorges Reservoir under varying reservoir water levels," Environmental Earth Sciences, vol. 79, no. 1, 2020.

[18] J. Tian, D. Xu, and T. Liu, “An experimental investigation of the fracturing behaviour of rock-like materials containing two V-shaped parallelogram flaws," International Journal of Mining Science and Technology, vol. 30, no. 6, pp. 777-783, 2020.

[19] Y. G. Zhang, S. Y. Zhu, J. K. Tan, L. D. Li, and X. J. Yin, "The influence of water level fluctuation on the stability of landslide in the Three Gorges Reservoir," Arabian Journal of Geosciences, vol. 13, no. 17, p. 845, 2020.

[20] Z. Tao, Y. Shu, X. Yang, Y. Peng, Q. Chen, and H. Zhang, "Physical model test study on shear strength characteristics of slope sliding surface in Nanfen open-pit mine," International Journal of Mining Science and Technology, vol. 30, no. 3, pp. 421-429, 2020.

[21] Y. G. Zhang, Y. Zhu, W. Q. Zhang, and H. Liu, “Analysis of deformation characteristics and stability mechanisms of typical landslide mass based on the field monitoring in the Three Gorges Reservoir, China," Journal of Earth System Science, vol. 128, no. 1, article 1036, 2019.

[22] Y. G. Zhang, X. Q. Chen, R. P. Liao et al., "Research on displacement prediction of step-type landslide under the influence of various environmental factors based on intelligent WCA-ELM in the Three Gorges Reservoir Area," Natural Harzard, vol. 109, article 4655, 2021.

[23] S. Chen, Z. Q. Yue, and L. G. Tham, "Digital image-based numerical modeling method for prediction of inhomogeneous rock failure," International Journal of Rock Mechanics and Mining Sciences, vol. 41, no. 6, pp. 939-957, 2004.

[24] C. Shi, W. Yang, J. Yang, and X. Chen, "Calibration of microscaled mechanical parameters of granite based on a bonded- 
particle model with 2D particle flow code," Granular Matter, vol. 21, no. 2, article 889, 2019.

[25] L. Jinzhao, J. Xu, and H. Dayong, "Particle flow simulation of granite deformation and failure process considering the actual distribution of mesoscopic components," in Proceedings of National Engineering Geology Annual Conference 2015, pp. 84-89, Beijing: China, 2015.

[26] G. Ma, W. Zhou, R. A. Regueiro, Q. Wang, and X. Chang, "Modeling the fragmentation of rock grains using computed tomography and combined FDEM," Powder Technology, vol. 308, no. 308, pp. 388-397, 2017.

[27] T. Xinwei, Z. Yuande, and Z. Chuhan, “A meso mechanical model with spatial correlation scale character and its application," Rock and Soil Mechanics, vol. 33, no. 7, pp. 2021-2026, 2012.

[28] T. Xinwei, H. Wenmin, and Z. Yuande, "Experimental and meso-scale numerical modeling of splitting tensile behavior of weathered granites from south China," Engineering Mechanics, vol. 34, no. 6, pp. 246-256, 2017.

[29] X. Tang, Y. Zhou, C. Zhang, and J. Shi, "Study on the heterogeneity of concrete and its failure behavior using the equivalent probabilistic model," Journal of materials in civil engineering, vol. 23, no. 4, pp. 402-413, 2011.

[30] X. Tang, X. Yang, and Y. Zhou, “An efficient algorithm for spatially-correlated random fields generation and its applications on the two-phase material," Solid State Communications, vol. 182, pp. 30-33, 2014.

[31] Y. Lv, H. Li, X. Zhu, and W. Liu, "Discrete element method simulation of random Voronoi grain-based models," Cluster Computing, vol. 20, no. 1, pp. 335-345, 2017.

[32] E. Ghazvinian, M. S. Diederichs, and R. Quey, “3D random Voronoi grain-based models for simulation of brittle rock damage and fabric-guided micro-fracturing," Journal of Rock Mechanics and Geotechnical Engineering, vol. 6, no. 6, pp. 506-521, 2014.

[33] J. Yang, H. Lian, and L. Lid, "Investigating the effect of confining pressure on fracture toughness of $\mathrm{CO}_{2}$-saturated coals," Engineering Fracture Mechanics, vol. 242, article 107496, 2021.

[34] J. Yang, H. Lian, and V. P. Nguyen, "Study of mixed mode I/II cohesive zone models of different rank coals," Engineering Fracture Mechanics, vol. 246, article 107611, 2021.

[35] J. Yang, H. Lian, and L. Li, "Fracturing in coals with different fluids: an experimental comparison between water, liquid $\mathrm{CO}_{2}$, and supercritical $\mathrm{CO}_{2}$," Scientific Reports, vol. 10, no. 1, article 18681, 2020.

[36] N. Cho, C. D. Martin, and D. C. Sego, "A clumped particle model for rock," International Journal Of Rock Mechanics And Mining Sciences, vol. 44, no. 7, pp. 997-1010, 2007.

[37] D. O. Potyondy, “A grain-based model for rock: approaching the true microstructure," in Proceedings of rock mechanics in the Nordic Countriespp. 9-12, Kongsberg, Norway, 2010.

[38] Y. Zhou, Y. T. Gao, S. C. Wu, Q. Yan, and H. Sun, “An equivalent crystal model for mesoscopic behavior of rock," Chinese Journal of Rock Mechanics and Engineering, vol. 34, no. 3, pp. 511-519, 2015.

[39] X. F. Li, Q. B. Zhang, H. B. Li, and J. Zhao, "Grain-based discrete element method (GB-DEM) modelling of multi-scale fracturing in rocks under dynamic loading," Rock Mechanics and Rock Engineering, vol. 51, no. 12, article 1566, pp. 37853817, 2018.
[40] Y. Zhang, L. N. Y. Wong, and K. K. Chan, “An extended grainbased model accounting for microstructures in rock deformation," Journal of Geophysical Research: Solid Earth, vol. 124, no. 1, pp. 125-148, 2019.

[41] S. P. Morgan, C. A. Johnson, and H. H. Einstein, "Cracking processes in Barre granite: fracture process zones and crack coalescence," International Journal of Fracture, vol. 180, no. 2, pp. 177-204, 2013.

[42] S. S. Lim, C. D. Martin, and U. Åkesson, "In-situ stress and microcracking in granite cores with depth," Engineering Geology, vol. 147-148, pp. 1-13, 2012.

[43] H. Zhang, M. Tu, H. Cheng, and Y. Tang, "Breaking mechanism and control technology of sandstone straight roof in thin bedrock stope," International Journal of Mining Science and Technology, vol. 30, no. 2, pp. 259-263, 2020.

[44] H. Lin, W. H. Kang, J. Oh, I. Canbulat, and B. Hebblewhite, "Numerical simulation on borehole breakout and borehole size effect using discrete element method," International Journal of Mining Science and Technology, vol. 30, no. 5, pp. 623-633, 2020.

[45] H. J. Wang, D. A. Liu, W. L. Gong, and L. Li, "Dynamic analysis of granite rockburst based on the PIV technique," International Journal of Mining Science and Technology, vol. 25, no. 2, pp. 275-283, 2015.

[46] H. Hofmann, T. Babadagli, J. S. Yoon, A. Zang, and G. Zimmermann, "A grain based modeling study of mineralogical factors affecting strength, elastic behavior and micro fracture development during compression tests in granites," Engineering Fracture Mechanics, vol. 147, pp. 261-275, 2015.

[47] N. Bahrani, P. K. Kaiser, and B. Valley, "Distinct element method simulation of an analogue for a highly interlocked, non-persistently jointed rockmass," International Journal of Rock Mechanics and Mining Sciences, vol. 71, pp. 117-130, 2014.

[48] Y. Wu, Y. Xu, X. Zhang et al., "Experimental study on vacuum preloading consolidation of landfill sludge conditioned by Fenton's reagent under varying filter pore size," Geotextiles and Geomembranes, vol. 49, no. 1, pp. 109-121, 2021.

[49] X. Hu, N. Xie, Q. Zhu, L. Chen, and P. C. Li, "Modeling damage evolution in heterogeneous granite using digital imagebased grain-based model," Rock Mechanics and Rock Engineering, vol. 53, no. 11, article 2191, pp. 4925-4945, 2020.

[50] T. Yin, S. Zhang, X. Li, and L. Bai, "A numerical estimate method of dynamic fracture initiation toughness of rock under high temperature," Engineering Fracture Mechanics, vol. 204, pp. 87-102, 2018.

[51] B. Shu, M. Liang, S. Zhang, and J. Dick, "Numerical modeling of the relationship between mechanical properties of granite and microparameters of the flat-joint model considering particle size distribution," Mathematical Geosciences, vol. 51, no. 3, pp. 319-336, 2019.

[52] E. Komurlu, A. Kesimal, and S. Demir, "Experimental and numerical study on determination of indirect (splitting) tensile strength of rocks under various load apparatus," Canadian Geotechnical Journal, vol. 53, no. 2, pp. 360-372, 2016.

[53] Y. G. Huang, L. G. Wang, Y. L. Lu, J. R. Chen, and J. H. Zhang, "Semi-analytical and numerical studies on the flattened Brazilian splitting test used for measuring the indirect tensile strength of rocks," Rock Mechanics and Rock Engineering, vol. 48, no. 5, pp. 1849-1866, 2015.

[54] H. Wenmin, Study on Deformation and Fracture-Damage Mechanism of Rock Based on the Spatial Correlation Characteristics, South China University of Technology, 2018. 